\title{
Right heart pressures in bronchial asthma
}

\author{
R. F. GUNSTONE \\ St. George's Hospital, London S.W.1
}

\begin{abstract}
Right heart pressures, electrocardiograms, blood gases, and peak expiratory flow rates were measured in nine patients admitted to hospital with severe bronchial asthma. Low or normal right heart pressures were found despite electrocardiographic changes in five patients consisting of right atrial $P$ waves, abnormal right axis deviation, and in one patient $T$-wave changes in precordial leads. These electrocardiographic changes reverted towards normal on recovery of the patient from the asthmatic attack.
\end{abstract}

Electrocardiographic changes suggestive of right heart embarrassment have been noted in acute bronchial asthma, particularly right atrial $\mathbf{P}$ waves ( $P$ pulmonale) and abnormal right axis deviation (Harkavy and Romanoff, 1942; Miyamato, Bastaroli, and Hoffman, 1961; Ambiavagar, Jones and Roberts, 1967). These observations raise the possibility that death in bronchial asthma may be due to acute cor pulmonale although necropsy evidence is against this suggestion (Earle, 1953 ; Houston, de Navasquez, and Trounce, 1953). Cardiac catheter studies in asthmatics have with few exceptions been made during remission of symptoms.

In the present study a miniature cardiac catheterization technique (Bradley, 1964) has been used to measure right heart pressures during acute attacks of asthma in an attempt to determine the significance of the electrocardiographic changes. The results have been assessed in relation to the blood gases and peak expiratory flow rates. All the patients had asthma (as defined by the Ciba Guest Symposium, 1959), some had additional chronic bronchitis (as defined by the Medical Research Council, 1965), and all had been admitted to hospital because of the severity of dyspnoea.

\section{METHODS}

An attempt was made by clinical examination, chest radiographs, and electrocardiograms to exclude cardiopulmonary disease other than bronchial asthma (with or without bronchitis). Patients received conventional treatment and the investigation was performed as soon as possible after admission and after a full explanation and request for co-operation. No patient under 21 years of age or with important psychogenic factors was asked to participate.
The procedure was carried out in the general ward with the patient in the sitting position supported at 60 to 90 degrees to the horizontal because orthopnoea was always present. Immediately after catheterization the peak expiratory flow rate was measured with a Wright peak flow meter (Wright and McKerrow, 1959) and blood (capillary or arterial) was taken for measurement of $\mathrm{pH}, \mathrm{PCO}_{2}$, and standard bicarbonate by the Astrup method (Astrup, Jørgensen, Andersen, and Engel, 1960). The peak flow rate and electrocardiogram were repeated after recovery. One patient (No. 5) was re-catheterized when she had recovered from her asthma.

Cardiac catheterization was carried out with a miniature disposable cardiac catheter (Portland Plastics Ltd.) inserted through a disposable Guest cannula (Capon Heaton Ltd.). The cannula was introduced percutaneously into a median antecubital vein under local anaesthesia. Right ventricular and/or pulmonary artery pressures were measured with an electromanometer and recorded together with a continuous electrocardiogram on a direct-writing Elema Schonander Minograf 34 Recorder (Siriex Ltd.). The sternomanubrial junction was used as the zero reference point.

\section{RESULTS}

Low or normal right heart pressures were recorded in all patients. The pressures fell even further on inspiration by as much as $20 \mathrm{mmHg}$ in the acute phase. These observations are illustrated in Figures 1B, 2B, and 3. Figure 3 also shows the prolonged expiration typical of bronchial asthma. Detailed results are given in the Table which emphasizes the reversible nature of the airways obstruction and describes the electrocardiograms. Electrocardiographic abnormalities were present in five of the nine patients but were no: associated with higher right heart pressures than in the other four. Right atrial $P$ waves and right 


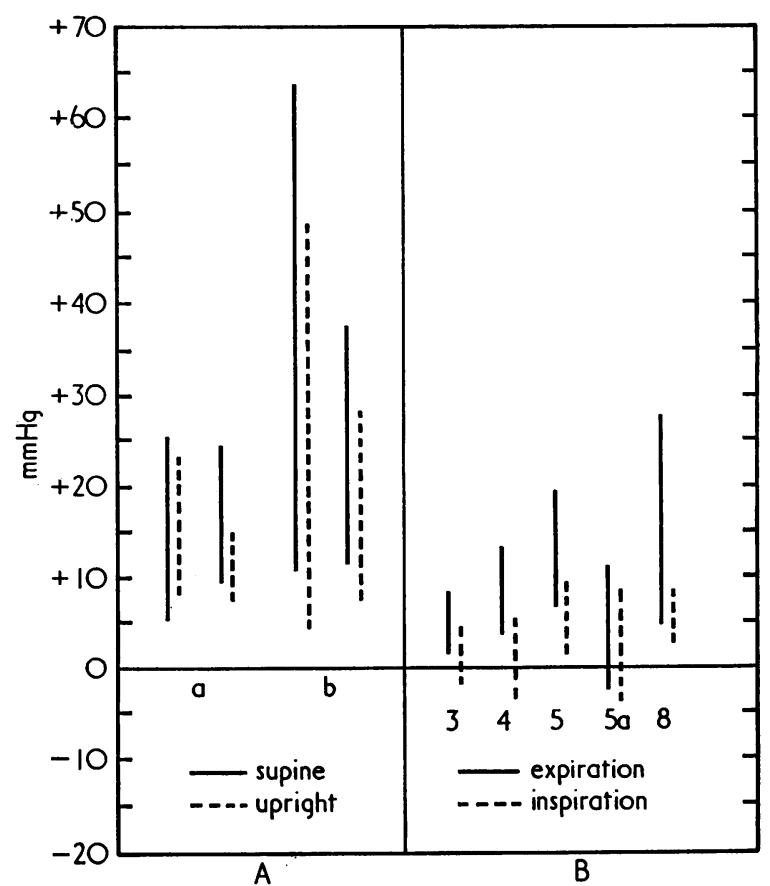

FIG. 1. Right ventricular pressures: A, Effect of posture (Donald et al. 1953) on (a) two normal subjects; (b) two patients with pulmonary hypertension. B, In four seated patients with acute bronchial asthma and one (5a) on recovery.

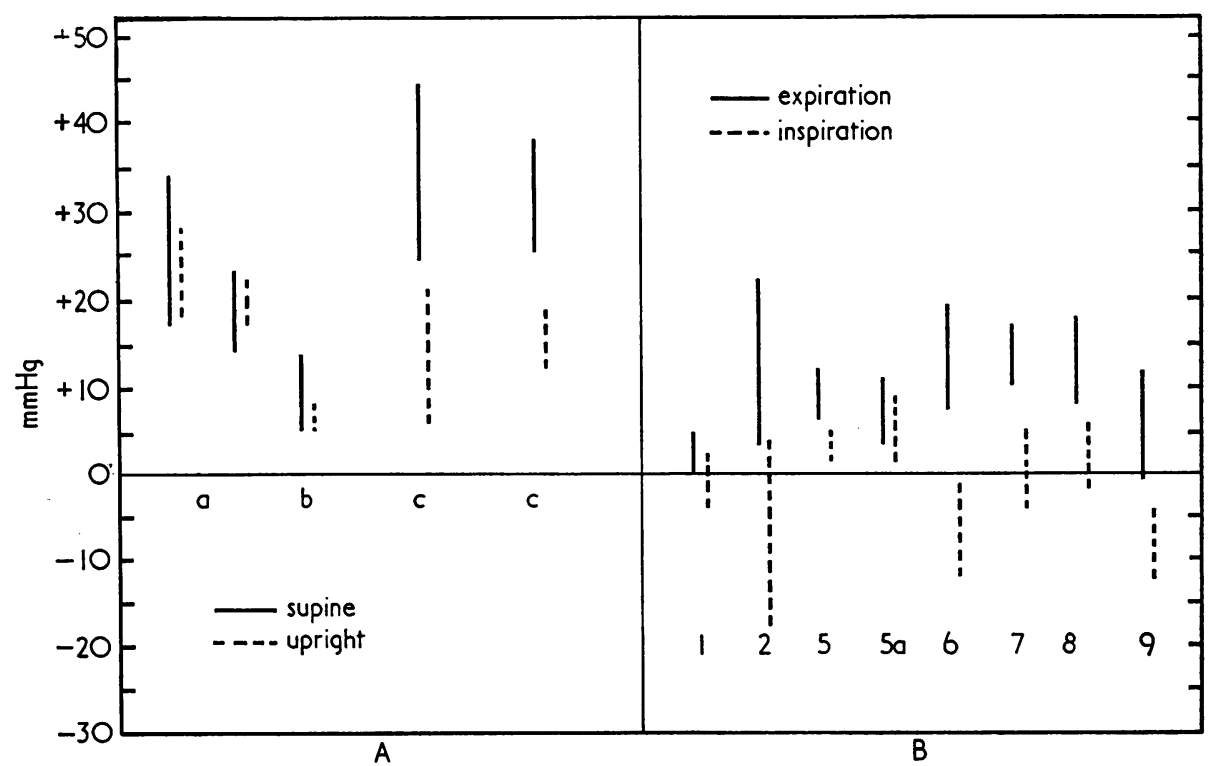

FIG. 2. Pulmonary artery pressure: A, Effect of posture on (a) two normal subjects (Donald et al. 1953); (b) one normal subject (Lagerlof et al. 1951); (c) two patients with pulmonary hypertension (Donald et al. 1953). B, in seven seated patients with acute bronchial asthma and one (5a) on recovery. 


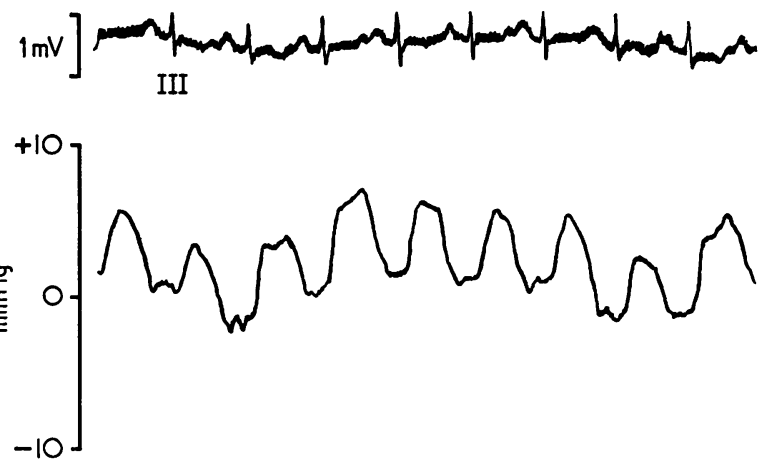

(a)

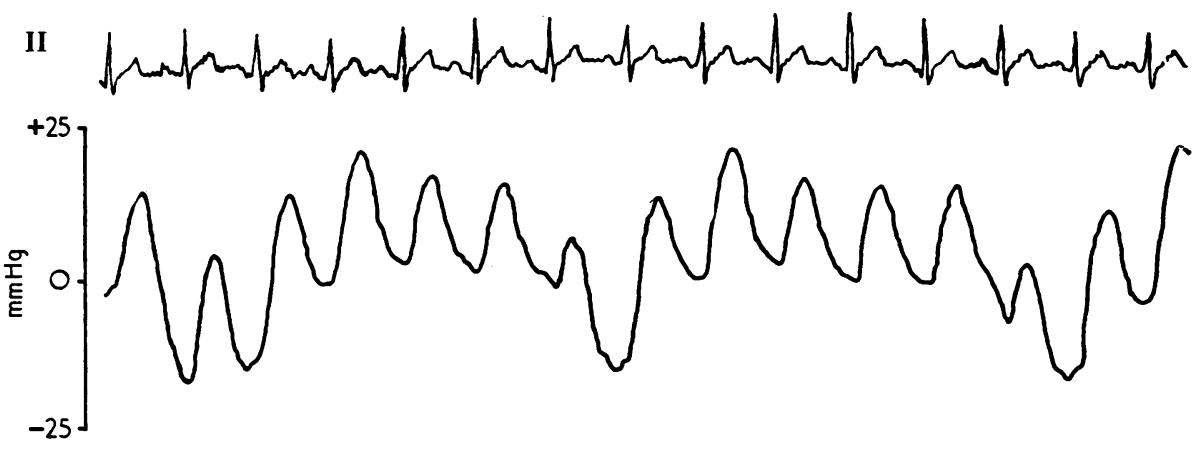

(b)
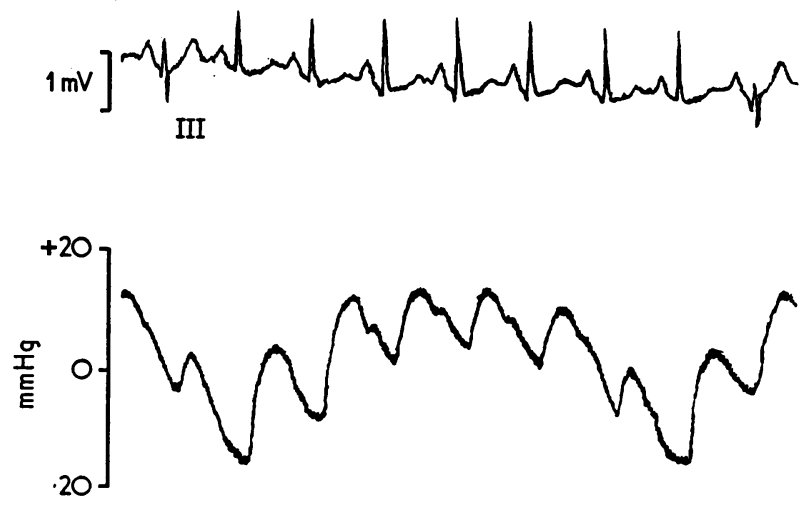

(c)

FIG. 3. (a) Right ventricular pressure tracing and electrocardiogram-patient 3. (b) Pulmonary artery pressure tracing and electrocardiogram-patient 2. (c) Pulmonary artery pressure tracing and electrocardiogram-patient 9. Note the inspiratory fall of pressure lasting a much shorter time than the expiratory rise. 


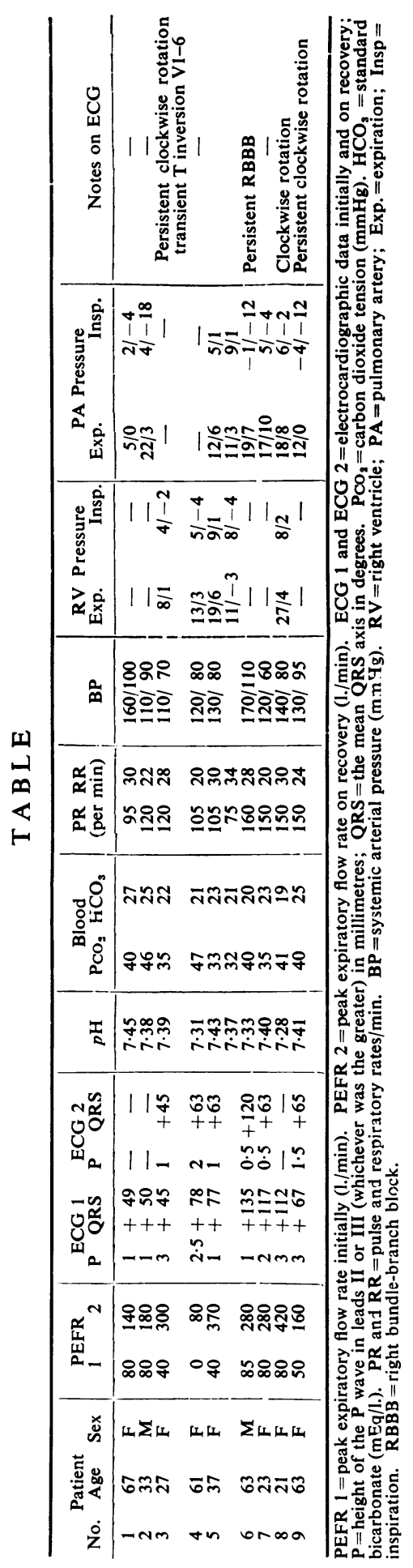




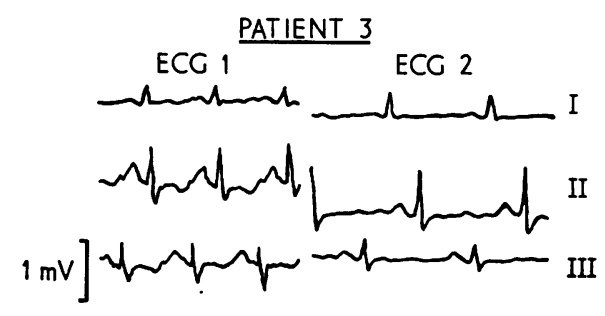

(a)
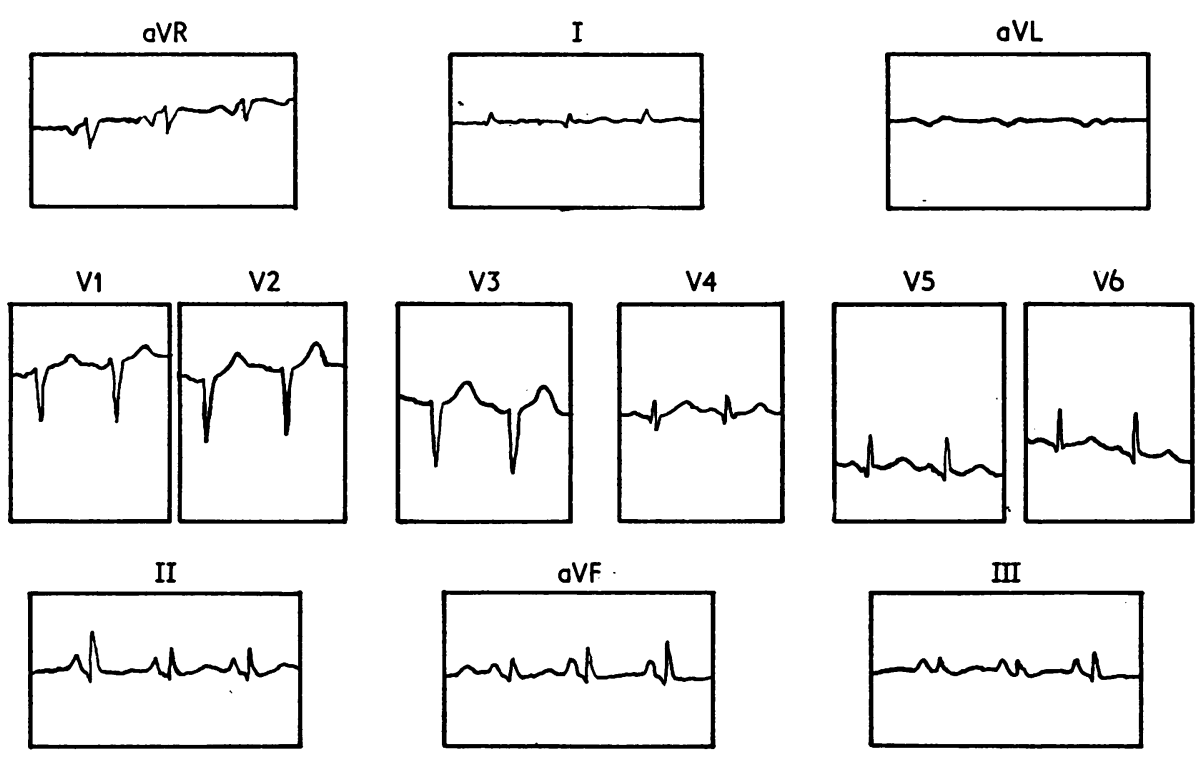

PATIENT 4 ECG 1

(b)
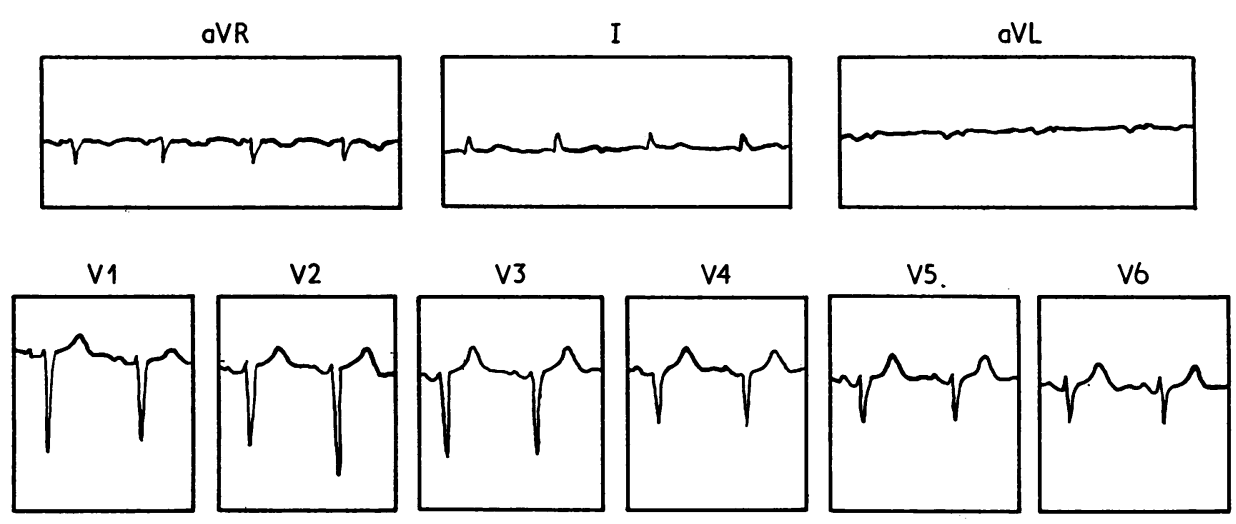

II

oritantarda

PATIENT 4 ECG 2
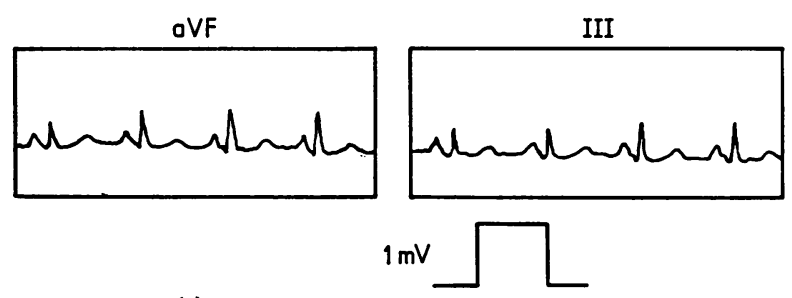

(c)

FIG. 4. Legend on page 44 . 

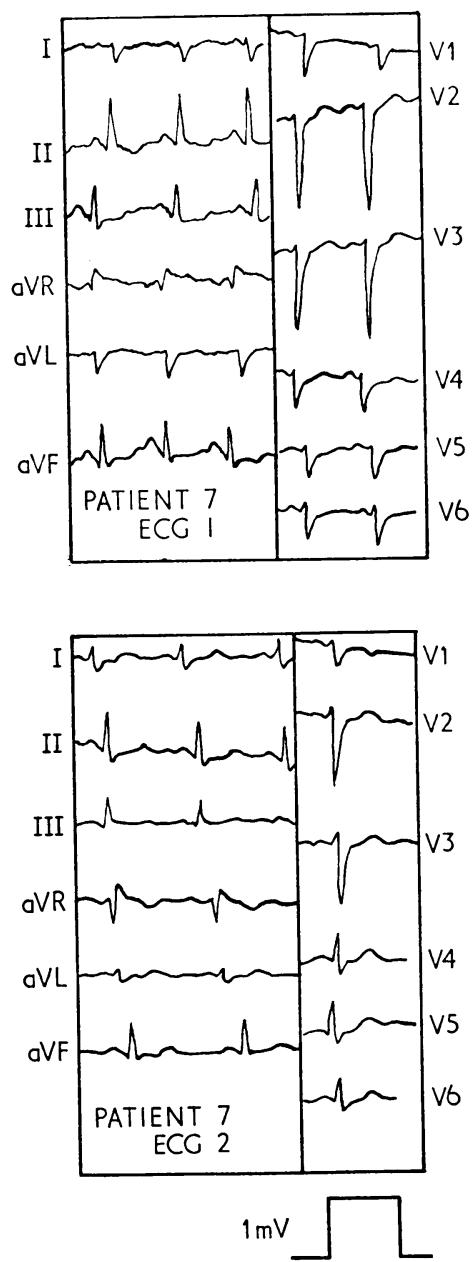

(d)

FIG. 4. Selected electrocardiograms of asthmatic patients. ECG 1, during acute asthma; ECG 2, on recovery.

axis deviation were the commonest changes observed and each of these might be present without the other (Fig. 4). Other features noted were clockwise rotation, right bundle-branch block, and $\mathrm{T}$-wave inversion. As indicated in the Table, most of these changes were transient.

Right heart pressures were uninfluenced by the small degrees of respiratory acidosis (patient 4 ) or the metabolic acidosis (patients 6 and 8).

\section{DISCUSSION}

The pressures recorded were surprisingly low in view of the electrocardiographic changes and do not agree with the findings of other workers, as discussed later. Pressure measurements made from the sternomanubrial junction as the zero reference $\frac{5}{5}$ point are about $4 \mathrm{mmHg}$ lower than those using $\frac{\bar{\omega}}{\bar{\omega}}$. the mid right atrium. However, even if this figure $\vec{\Phi}_{\mathbb{D}}$ is added, the highest pressure recorded was only $31 / 8 \mathrm{mmHg}$.

Most cardiac catheterizations are carried out on $\vec{\circ}$ supine subjects, whereas in this study the asth- $-\overrightarrow{-}$ matics could not lie flat. The effect of posture on $\vec{\sigma}$ right heart pressures has been studied by Donald, $\overrightarrow{\vec{*}}$ Bishop, Cumming, and Wade (1953) and by $\times$ Lagerlöf, Eliasch, Werkö, and Berglund (1951) (Figs 1a and 2a): on sitting up from the supineposition the pulse pressure fell in all patients stu- $\omega$ died, but in patients with pulmonary hypertension? the systolic and diastolic pressures both fell. It isan open question, therefore, whether the pressuresc in the present series would be higher had the? patients been flat, as they were in the studies now to be discussed.

Williams and Zohman (1960) and Irnell (1964) $\overrightarrow{0}$ noted moderate pulmonary hypertension on exer-cise in some but not all of the asthmatic patients they studied. Zimmerman (1951) and Helander, Lindell, Söderholm, and Westling (1962) noted aㅡㅡㅇ rise in pulmonary artery pressure in half of theiro patients in whom asthmatic attacks had been arti- $\frac{\Omega}{2}$ ficially induced. These patients were studied in the supine position; patients in whom bronchocon $\frac{0}{3}$ striction is artificially induced may be distressed by the need to remain flat and this could con tribute to the rise in pulmonary artery pressure Harris and Heath (1962a) state that the pulmonaryo circulation, like the systemic circulation, is influ enced by emotional factors.

All the 14 patients studied by Helander et al 3 . showed systemic arterial desaturation, only two having an oxygen saturation of more than $92 \%$ during the induced attack. Ambiavagar et alo (1967) report a patient in status asthmaticus and respiratory failure $\left(\mathrm{PCO}_{2} 75 \mathrm{mmHg}\right.$ and $\mathrm{Po}_{2} 945$ $\mathrm{mmHg}$ while breathing oxygen) whose right ven $\overline{\overline{\bar{N}}}$ tricular pressure (measured with the patient reø clining at 45 degrees) was $50 / 10$ on expiration and $20 / 20$ on inspiration. This patient was fañ more ill than any in the present series and subse quently required artificial ventilation.

The pulmonary hypertension noted by other observers in bronchial asthma could be due to̊ hypoxaemia, which is commoner in bronchial asthma than was once thought (Palmer and Diao ment, 1967 ; Tai and Read, 1967 ; Waddell, Emerब्ञ son, and Gunstone, 1967). In this present stud arterial oxygen was not measured but an attemp? was made to eliminate hypoxaemia. Harris an\& 
Heath (1962b) reviewed the literature concerning the effect of oxygen on the pulmonary circulation and stated that, as well as oxygen, isoprenaline and aminophylline can lower the pulmonary artery pressure. All the patients in the present series were treated with one or more of these three agents, so in the completely untreated patient pulmonary artery pressures might indeed have been higher. Yet despite treatment severe bronchial obstruction persisted throughout the catheterization as did the electrocardiographic changes.

The absence of pulmonary hypertension leaves undetermined the cause of these changes. The over-distension of the lungs and descent of the diaphragm might account for the axis changes but the right atrial $\mathbf{P}$ waves and other changes are less easily explained. Relevant to this discussion is the observation by Mayerson and Davis (1942) that in normal subjects passive tilting to the vertical position caused the following electrocardiographic changes - an increase in the amplitude of the $P$ waves, a decrease in the amplitude of the $T$ waves, and a shift of the QRS axis to the right and of the T-wave axis to the left. They quote observations suggesting that sympathetic activity may be partly responsible for these changes. That the position of the heart changes considerably in bronchial asthma is well demonstrated in the chest radiographs reproduced by Riding and Ambiavagar (1967). Furthermore, an erect posture is usually assumed by patients with severe bronchospasm in whom there is much sympathetic (or sympathomimetic) activity.

The expenses of this study were met by a grant from the Research Committee of St. George's Hospital, London. I am indebted to Dr. J. C. Batten and Dr. Aubrey Leathem for encouragement and advice.

I wish to thank the following physicians for permission to study patients under their care: Dr. J. C. Batten, Dr. J. Dow, Dr. J. Jenkins, and Sir Kenneth Robson, of St. George's Hospital ; and Dr. W. D. Brinton and Dr. D. A. F. McGill, of the Royal Hampshire County Hospital, Winchester. Thanks are also due to Mr. W. Serumaga, of the Department of Medical Illustration, Makerere University College, Kampala, for the figures.

\section{REFERENCES}

Ambiavagar, M., Jones, E. S., and Roberts, D. V. (1967). Intermittent positive pressure ventilation in severe asthma. Mechanical effects on the circulation. Anaesthesia, 22, 134.
Astrup, P., Jørgensen, K., Andersen, O. S., and Engel, K. (1960). The acid-base metabolism-a new approach. Lancet, 1, 1035.

Bradley, R. D. (1964). Diagnostic right-heart catheterisation with miniature catheters in severely ill patients. Lancet, 2, 941 .

Ciba Guest Symposium (1959). Terminology, definitions, and classification of chronic pulmonary emphysema and related conditions. Thorax, 14, 286.

Donald, K. W., Bishop, J. M., Cumming, G., and Wade, O. L. (1953). The effect of nursing positions on the cardiac output in man. Clin. Sci., 12, 199.

Earle, B. V. (1953). Fatal bronchial asthma. Thorax, 8, 195.

Harkavy, J., and Romanoff, A. (1942). Electrocardiographic changes in bronchial asthma and their significance. Amer. Heart J., 23, 692.

Harris, P., and Heath, D. (1962a). The Human Pulmonary Circulation: its Form and Function in Health and Disease, p. 102. Livingstone, Edinburgh.

(1962b). The Human Pulmonary Circulation: its Form and Function in Health and Disease, pp. 117, 121, 127. Livingstone, Edinburgh.

Helander, E., Lindell, S-E., Söderholm, B., and Westling, H. (1962). Observations on the pulmonary circulation during induced bronchial asthma. Acta allerg. (Kbh.), 17, 112.

Houston, J. C., de Navasquez, S., and Trounce, J. R. (1953). A clinical and pathological study of fatal cases of status asthmaticus. Thorax, 8, 207.

Irnell, L. (1964). A Study of bronchial asthma. Acta med. scand., Suppl. 419.

Lagerlöf, H., Eliasch, H., Werkö, L., and Berglund, E. (1951). Orthostatic changes of the pulmonary and peripheral circulation in man. Scand. J. clin. Lab. Invest., $3,85$.

Mayerson, H. S., and Davis, W. D. (1942). The influence of posture on the electrocardiogram. Amer. Heart J., 24, 593.

Medical Research Council (1965). Definition and classification of chronic bronchitis for clinical and epidemiological purposes. Lancet, 1, 775.

Miyamoto, T., Bastaroli, J., and Hoffman, M. S. (1961). Electrocardiographic changes in induced bronchial asthma. Jap. Heart J., 2, 524.

Palmer, K. N. V., and Diament, M. L. (1967). Spirometry and blood-gas tensions in bronchial asthma and chronic bronchitis. Lancet, 2, 383.

Riding, W. D., and Ambiavagar, M. (1967). Resuscitation of the moribund asthmatic. Postgrad. med. J., 43, 234.

Tai, E., and Read, J. (1967). Blood-gas tensions in bronchial asthma. Lancet, $1,644$.

Waddell, J. A., Emerson, P. A., and Gunstone, R. F. (1967). Hypoxia in bronchial asthma. Brit. med. J., 2, 402.

Williams, M. H., Jr., and Zohman, L. R. (1960). Cardiopulmonary function in bronchial asthma. Amer. Rev. resp. Dis., 81, 173.

Wright, B. M., and McKerrow, C. B. (1959). Maximum forced expiratory flow rate as a measure of ventilatory capacity. Brit. med. J., 2, 1041.

Zimmerman, H. A. (1951). A study of the pulmonary circulation in man. Dis. Chest, 20, 46. 